\title{
Effect of Annealing Process on Magnetic Properties, Structures and Coercivity Mechanism in Nanocrystalline $\mathrm{Pr}_{8} \mathrm{Dy}_{1} \mathrm{Fe}_{60} \mathrm{Co}_{7} \mathrm{M}_{3} \mathrm{Ni}_{3} \mathrm{~B}_{14} \mathrm{Zr}_{1} \mathrm{Ti}_{3}$ Alloy Ribbons
}

\author{
A. PRZYBYє* \\ Department of Physics, Faculty of Production Engineering and Materials Technology, \\ Częstochowa University of Technology, al. Armii Krajowej 19, 42-200 Częstochowa, Poland \\ Doi: $10.12693 /$ APhysPolA.138.144 \\ *e-mail: przybyl.anna@wip.pcz.pl
}

\begin{abstract}
The aim of this paper was to study the phase constitution, magnetic properties, and magnetization reversal processes in the $\operatorname{Pr}_{8} \mathrm{Dy}_{1} \mathrm{Fe}_{60} \mathrm{Co}_{7} \mathrm{Mn}_{3} \mathrm{Ni}_{3} \mathrm{~B}_{14} \mathrm{Zr}_{1} \mathrm{Ti}_{3}$ alloy ribbons. The ingot samples were obtained by arc-melting of high purity constituent elements. The single roll spinning technique was used for producing rapidly solidified ribbons. Melt-spun ribbons were produced from the base alloy at the different surface velocity of the copper wheel. Subsequently, the fully amorphous ribbons were subjected to annealing at various temperatures from 923 to $1023 \mathrm{~K}$ for $5 \mathrm{~min}$ and then cooled in ice water. The X-ray diffraction was used to determine phase constitution of all obtained samples. Nanocomposite structure of produced ribbons was obtained during short-time annealing. The magnetic parameters were determined from magnetic hysteresis loops measured in the external magnetic field up to $2 \mathrm{~T}$ at room temperature. In order to clarify the occurrence of possible interactions, the Henkel plots were constructed.
\end{abstract}

topics: hard magnetic materials, melt-spun ribbons, magnetic properties, Henkel plots

\section{Introduction}

The RE-Fe-B type magnets have been studied for four decades. They are used in motors, turbines and micromotors using in electronics industry $[1,2]$. The changes of chemical composition are tuning the structure and magnetic properties this type of magnets [3-5]. An interesting group of $\mathrm{RE}-\mathrm{Fe}-\mathrm{B}$ permanent magnets is a nanocrystalline alloy based on the interaction between soft magnetic $\alpha$-Fe or $\mathrm{Fe}_{3} \mathrm{~B}$ phases with hard magnetic $\mathrm{RE}_{2} \mathrm{Fe}_{14} \mathrm{~B}$ phase [6-8]. Such interaction results in higher saturation magnetization in comparison to single phase $\mathrm{RE}_{2} \mathrm{Fe}_{14} \mathrm{~B}$ alloy $[9,10]$. The influence of substitution of $\mathrm{Fe}$ by $\mathrm{Ni}$ or $\mathrm{Mn}$ was investigated in previous paper [11]. An increase of coercivity was observed while Mn content rosed. These alloys were produced using suction-casting (plates and tubes) and meltspinning techniques. Other previous papers concerned reversal magnetic processes of samples produced by a suction-casting method in the form of tubes and plates $[12,13]$. According to the hypothesis that the structure and magnetic properties of the material may strongly depend on their obtaining method, the investigations of material in a form of ribbon, prepared by melt-spinning technique was carried out in the present paper.

\section{Samples preparation} and experimental methods

Starting ingot with a nominal composition of $\mathrm{Pr}_{8} \mathrm{Dy}_{1} \mathrm{Fe}_{60} \mathrm{Co}_{7} \mathrm{M}_{3} \mathrm{Ni}_{3} \mathrm{~B}_{14} \mathrm{Zr}_{1} \mathrm{Ti}_{3}$, was prepared by arc melting of high purity constituent elements under low pressure of Ar. Samples were re-melted several times to get homogeneity. Parts of these ingots are then melt-spun in an argon atmosphere by ejecting molten alloy through a nozzle in quartz crucible onto the edge of a rotating copper wheel. The cooling rate changes as the linear speed of the cooling wheel $\left(V_{s}\right)$ changes, while maintaining all other experimental parameters. By varying the linear velocity of the copper wheel from 4 to $30 \mathrm{~m} / \mathrm{s}$ the ribbons of various thicknesses (from $\approx 94 \mu \mathrm{m}$ to $25 \mu \mathrm{m}$ ) were produced. The fully amorphous $\approx 25 \mu \mathrm{m}$ thick ribbons were sealed in a quartz tube in a protective argon atmosphere and annealed at various temperatures from $923 \mathrm{~K}$ to $1023 \mathrm{~K}$ for $5 \mathrm{~min}$ and then cooled in ice water.

The prepared samples were examined using a Bruker D8 Advance X-ray diffractometer with $\mathrm{CuK}_{\alpha}$ radiation to determine the phase structure of alloys. The magnetic properties of the alloys were determined using LakeShore VSM 7307 vibrating sample magnetometer in an external magnetic field up to $2 \mathrm{~T}$ at room temperature.

To clarify the occurrence of possible interactions, the Henkel plots were constructed.

\section{Results and discussion}

In order to prepare fully amorphous alloy $\mathrm{Pr}_{8} \mathrm{Dy}_{1} \mathrm{Fe}_{60} \mathrm{Co}_{7} \mathrm{Mn}_{3} \mathrm{Ni}_{3} \mathrm{~B}_{14} \mathrm{Zr}_{1} \mathrm{Ti}_{3}$, four different speeds of copper wheel were used during melt spinning process. With the increase of the linear 

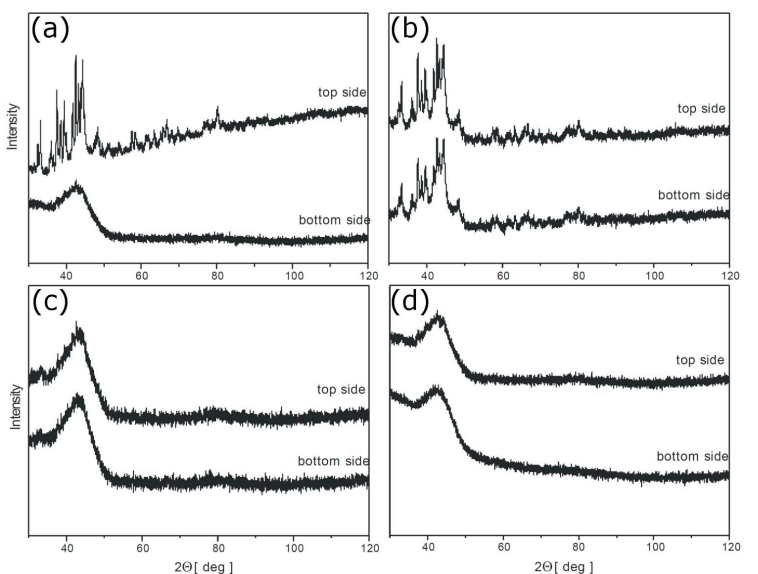

Fig. 1. XRD scans measured for the $\mathrm{Pr}_{8} \mathrm{Dy}_{1} \mathrm{Fe}_{60} \mathrm{Co}_{7} \mathrm{Mn}_{3} \mathrm{Ni}_{3} \mathrm{~B}_{14} \mathrm{Zr}_{1} \mathrm{Ti}_{3}$ as-cast ribbon samples of various thicknesses: $(\mathrm{a}) \approx 94 \mu \mathrm{m}$, (b) $\approx 72 \mu \mathrm{m},(\mathrm{c}) \approx 42 \mu \mathrm{m},(\mathrm{d}) \approx 25 \mu \mathrm{m}$.

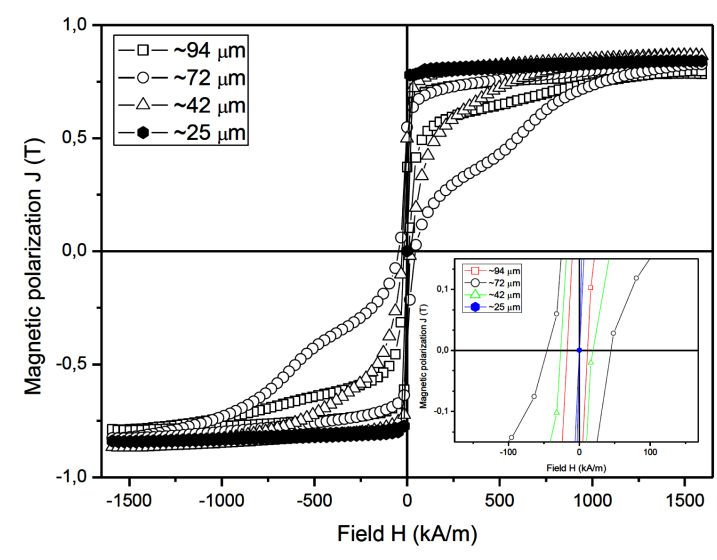

Fig. 2. Major hysteresis loops measured for the $\mathrm{Pr}_{8} \mathrm{Dy}_{1} \mathrm{Fe}_{60} \mathrm{Co}_{7} \mathrm{Mn}_{3} \mathrm{Ni}_{3} \mathrm{~B}_{14} \mathrm{Zr}_{1} \mathrm{Ti}_{3}$ alloy in the form of ribbons in as-cast state of various thicknesses and the insets show coercivity values for all samples.

velocity of the copper wheel from 4 to $30 \mathrm{~m} / \mathrm{s}$ the ribbons thickness decreased from $\approx 94 \mu \mathrm{m}$ to $25 \mu \mathrm{m}$. To indicate the maximum thicknesses of fully glassy samples the X-ray diffraction (XRD) studies were performed on as-cast ribbon samples of various thicknesses. The measurements were carried out on both surfaces of the ribbons: the side in thermal contact with copper roll during meltspinning (bottom side) and on the free surface of the ribbon (top side).

The diffraction spectra measured on top and bottom sides of the as-cast ribbons of various thicknesses are presented in Fig. 1. The $25 \mu \mathrm{m}$ thick ribbon was fully amorphous on both sides of the sample. The XRD scans measured for other ribbons show that they are partially crystalline.

In Fig. 2 the hysteresis loops measured for ascast ribbons of various thicknesses are presented. The hysteresis loops were typical for the soft

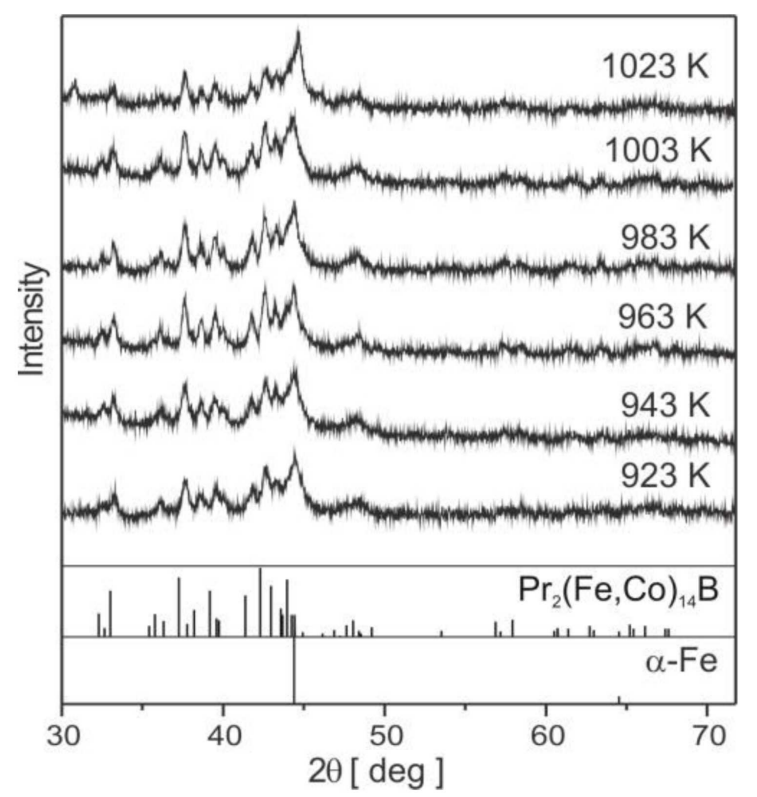

Fig. 3. The XRD patterns of the alloy ribbons $\mathrm{Pr}_{8} \mathrm{Dy}_{1} \mathrm{Fe}_{60} \mathrm{Co}_{7} \mathrm{Mn}_{3} \mathrm{Ni}_{3} \mathrm{~B}_{14} \mathrm{Zr}_{1} \mathrm{Ti}_{3}$ annealed at various temperatures from $923 \mathrm{~K}$ to $1023 \mathrm{~K}$ for $5 \mathrm{~min}$.

magnetic materials. The insets show coercivity values for all samples. Slight differences in shape of hysteresis loops result from the presence of some volumes of crystalline phases in the alloy and might be related to different strains induced during rapid solidification.

Subsequently the fully amorphous ribbons $(\approx 25 \mu \mathrm{m})$ were annealed at temperatures ranging from $923 \mathrm{~K}$ to $1023 \mathrm{~K}$ for $5 \mathrm{~min}$ and examined with XRD (Fig. 3). Phase analysis indicated the presence of hard magnetic $\operatorname{Pr}_{2}(\mathrm{Fe}, \mathrm{Co}){ }_{14} \mathrm{~B}$ and soft magnetic $\alpha$-Fe phase for all annealing temperatures. To determine the ratio of soft to hard magnetic crystal phases, the Rietveld analysis was performed for all XRD scans. As the annealing temperature increases, no significant changes are observed in the phase composition of the alloys tested, the ratio of the hard magnetic to soft magnetic phase $\mathrm{Pr}_{2}(\mathrm{Fe}, \mathrm{Co}){ }_{14} \mathrm{~B} / \alpha$-Fe $(90 / 10)$ remains almost constant. Only in sample annealed at temperatures $1023 \mathrm{~K}$ an increase in the content of soft magnetic phase $\alpha$-Fe to $28 \%$ was observed. It was calculated that for all alloys annealed at different temperatures, the lattice constant $\alpha$-Fe $(a=$ $2.86 \AA$ ) remains unchanged. However, in the case of the $\operatorname{Pr}_{2}(\mathrm{Fe}, \mathrm{Co})_{14} \mathrm{~B}$ phase, lattice constant $a$ of $\approx 8.8 \AA$ and $c$ of $12.17 \AA$ were found. Changing the $c$ parameter in the hard magnetic phase of $\mathrm{Pr}_{2} \mathrm{Fe}_{14} \mathrm{~B}$ suggests that the unit cell is only modified by Co atoms and no other elements go into the unit cell.

The hysteresis loops measured for the samples annealed at various temperatures are presented in Fig. 4. Corresponding magnetic parameters are also collected in Table I. 


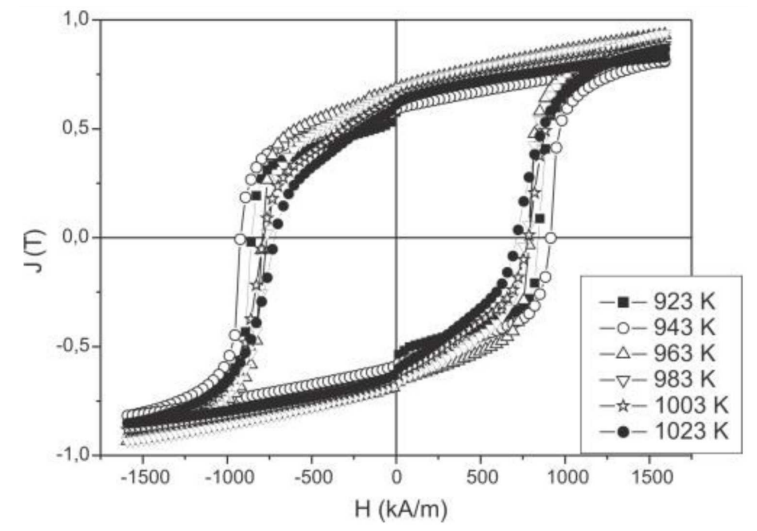

Fig. 4. Major hysteresis loops measured for the $\mathrm{Pr}_{8} \mathrm{Dy}_{1} \mathrm{Fe}_{60} \mathrm{Co}_{7} \mathrm{Mn}_{3} \mathrm{Ni}_{3} \mathrm{~B}_{14} \mathrm{Zr}_{1} \mathrm{Ti}_{3}$ alloy annealed at various temperatures from $923 \mathrm{~K}$ to $1023 \mathrm{~K}$ for $5 \mathrm{~min}$.

TABLE I

Magnetic properties of the investigated alloy, $\mathrm{Pr}_{8} \mathrm{Dy}_{1} \mathrm{Fe}_{60} \mathrm{Co}_{7} \mathrm{Mn}_{3} \mathrm{Ni}_{3} \mathrm{~B}_{14} \mathrm{Zr}_{1} \mathrm{Ti}_{3}$, annealed at various temperatures $T$ from $923 \mathrm{~K}$ to $1023 \mathrm{~K}$ for $5 \mathrm{~min}$

\begin{tabular}{c|c|c|c|c}
\hline \hline $\begin{array}{c}T \\
{[\mathrm{~K}]}\end{array}$ & $\begin{array}{c}J_{C} H_{C} \\
{[\mathrm{kA} / \mathrm{m}]}\end{array}$ & $\begin{array}{c}J_{r} \\
{[\mathrm{~T}]}\end{array}$ & $J_{r} / J_{s}$ & $\begin{array}{c}(B H)_{\max } \\
{\left[\mathrm{kJ} / \mathrm{m}^{3}\right]}\end{array}$ \\
\hline 923 & 856 & 0.571 & 0.69 & 47 \\
943 & 920 & 0.587 & 0.72 & 57.3 \\
963 & 792 & 0.681 & 0.73 & 74.2 \\
983 & 776 & 0.673 & 0.72 & 70 \\
1003 & 786 & 0.645 & 0.73 & 60.2 \\
1023 & 716 & 0.667 & 0.73 & 51.6
\end{tabular}

The basic magnetic parameters were determined from the hysteresis loops measured at room temperature in external magnetic fields up to $1600 \mathrm{kA} / \mathrm{m}$. The hysteresis loops were typical for the hard magnetic and two phases materials. The maximum value of the coercivity ${ }_{J} H_{c}=920 \mathrm{kA} / \mathrm{m}$ was obtained for a sample annealed at $943 \mathrm{~K}$ with the value of polarization remanence $J_{r}=0.587$ and maximum energy product $(B H)_{\max }=57.3 \mathrm{~kJ} / \mathrm{m}^{3}$ (Table I). With increase of annealing temperature, decrease of values of coercivity was observed. The best magnetic parameters were determined for sample annealed at temperature $963 \mathrm{~K}\left({ }_{J} H_{C}=792 \mathrm{kA} / \mathrm{m}\right.$, $J_{r}=0.681 \mathrm{~T}$ and $\left.(B H)_{\max }=74.2 \mathrm{~kJ} / \mathrm{m}^{3}\right)$. For all investigated samples the enhancement of remanence was observed $\left(J_{r} / J_{s}>0.5\right)$ which indicates the occurrence of exchange-coupling in the ribbons [9]. In order to confirm the existence of exchange-coupling the $\delta M$ plots $(\delta M(H))$ were constructed (Fig. 5). The $\delta M$ plots $(\delta M(H))$ were carried out using formula $\delta M=m_{d}(H)-\left(1-2 m_{r}(H)\right)$, where $m_{d}(H)$ is reduced demagnetization remanent (DCD) acquired after saturation in one direction and then the subsequent application and removal of a direct field $H$ in the reverse direction and $m_{r}(H)$ is the reduced isothermal remanence (IRM) acquired after the application and subsequent removal of a field $H$ [14].

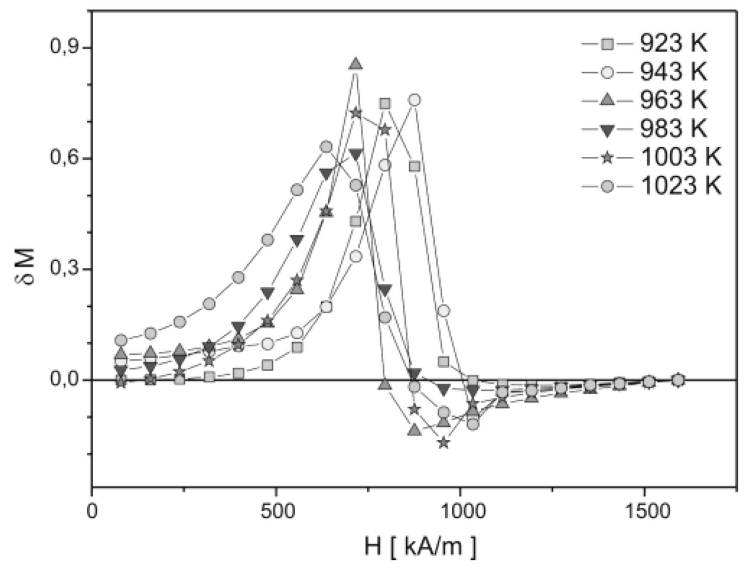

Fig. 5. dependence of $H$ on $\delta M$ for the $\mathrm{Pr}_{8} \mathrm{Dy}_{1} \mathrm{Fe}_{60} \mathrm{Co}_{7} \mathrm{Mn}_{3} \mathrm{Ni}_{3} \mathrm{~B}_{14} \mathrm{Zr}_{1} \mathrm{Ti}_{3}$ alloy annealed at various temperatures from $923 \mathrm{~K}$ to $1023 \mathrm{~K}$ for $5 \mathrm{~min}$.

A positive peak occurring around the coercive field was observed for all samples. The maximum values of $\delta M$ parameters are comparable for all alloys annealed at various temperatures from $923 \mathrm{~K}$ to $1023 \mathrm{~K}$ for $5 \mathrm{~min}$ which indicates that the strength of exchange-coupling is the same independent of annealing temperature. In higher external magnetic field the weak magnetostatic interaction was observed, which is associated with the negative deviation of $\delta M$ value.

\section{Conclusions}

In the present paper, the influence of annealing on structure and magnetic properties was investigated. Structural studies showed a coexistence of hard magnetic $\mathrm{Pr}_{2} \mathrm{Fe}_{14} \mathrm{~B}$ and soft magnetic $\alpha$-Fe phases. The analysis of the XRD patterns did not reveal any significant changes in cell parameters of detected phases. The highest coercivity was observed for sample annealed at $943 \mathrm{~K}$, while the highest remanence was determined. The best magnetic properties were designated for ribbon annealed at $963 \mathrm{~K}$. Moreover, the Henkel plots, constructed for investigated samples, confirmed that annealing had not influence on exchange-coupling observed in produced ribbons.

\section{References}

[1] M. Sagawa, S. Fujimura, H. Yamamoto, Y. Matsuura, K. Hiraga, IEEE Trans. Magn. 20, 1584 (1984).

[2] O. Gutfleisch, M.A. Willard, E. Brück, C.H. Chen, S.G. Sankar, J.P. Liu, Adv. Mater. 23, 821 (2011).

[3] M. Szwaja, P. Gębara, J. Filipecki, K. Pawlik, A. Przybył, P. Pawlik, J. Wysłocki, K. Filipecka, J. Magn. Magn. Mater. 382, 307 (2015). 
[4] K. Błoch, M. Nabiałek, Acta Phys. Pol. A 127, 413 (2015).

[5] M. Nabiałek, B. Jeż, K. Błoch, P. Pietrusiewicz, J. Gondro, J. Magn. Magn. Mater. 477, 214 (2019).

[6] D.C. Jiles, Acta Mater. 51, 5907 (2003).

[7] I. Betancourt, H.A. Davies, Mater. Sci. Technol. 26, 5 (2010).

[8] C. Ji, J. Yang, W. Mao, Y. Yang, Solid State Commun. 111, 113 (1999).

[9] V. Neu, P. Crespo, R. Schäfer, J. Eckert, L. Schultz, J. Magn. Magn. Mater. 157/158, 61 (1996).

[10] O.V. Billoni, E.E. Bordone, S.E. Urreta, L.M. Fabietti, H.R. Bertorello, J. Magn. Magn. Mater. 208, 1 (2000).
[11] A. Przybył, K. Pawlik, P. Pawlik, P. Gębara, J.J. Wysłocki, J. Alloys Compd. 536S, S333 (2012).

[12] A. Przybył, K. Pawlik, P. Pawlik, P. Gębara, J.J. Wysłocki, Acta Phys. Pol. A 127, 579 (2015).

[13] A. Przybył, I. Wnuk, J.J. Wysłocki, Rev. Chim. 70, 4086 (2019).

[14] P.E. Kelly, K. O'Grady, P.I. Mayo, R.W. Chantrell, IEEE Trans. Magn. 25, 3881 (1989). 